\title{
Parenting Sense of Competence in Parents of Children With and Without Intellectual Disability
}

\author{
Sanja Jandrić ${ }^{1,2}$, Ana Kurtović ${ }^{3}$ \\ [1] Unit for Child and Adolescent Psychiatry, Clinical Hospital Center, Osijek, Croatia. [2] Faculty of Medicine, 7. 7. Strossmayer University of Osijek, Osijek, \\ Croatia. [3] Department of Psychology, Faculty of Humanties and Social Sciences, Osijek, Croatia.
}

Europe's Journal of Psychology, 2021, Vol. 17(2), 75-91, https://doi.org/10.5964/ejop.3771

Received: 2020-05-27 • Accepted: 2020-09-02 • Published (VoR): 2021-05-31

Handling Editor: Aleksandra Gajda, The Maria Grzegorzewska University, Warsaw, Poland

Corresponding Author: Ana Kurtović, Department of Psychology, Faculty of Humanties and Social Sciences, L. Jagera 9, 31000 Osijek, Croatia. E-mail: akurtovi@ffos.hr

\begin{abstract}
Our study aims to examine the relationship of child's intellectual disability, parental education, employment and perceived stress with parenting sense of competence (satisfaction and self-efficacy). Three groups of parents (children without intellectual disability, children with mild intellectual disabilities, and children with moderate/severe intellectual disability) completed measures of perceived stress, parenting sense of competence and socio-demographic questions. Results show that child's intellectual disability affects parenting satisfaction but not parenting self-efficacy. Parental employment predicted parenting satisfaction, but not parenting selfefficacy, while perceived stress predicted parenting satisfaction and self-efficacy. Results further suggest that parental employment moderates the relationship of child's disability with parenting satisfaction and perceived stress. Result suggest a need for interventions aimed at supporting parents in dealing with emotional consequences of their child's disability.
\end{abstract}

\section{Keywords}

parenting sense of competence, perceived stress, intellectual disability

Children's well-being is closely related to parents' well-being, and most studies demonstrate that the quality of parental care, which greatly determines the child's adjustment, is influenced by parents' sense of competence in their role as parents (Coleman \& Karraker, 1997; Elek, Hudson \& Bouffard, 2003; Greenspan \& Wieder 2003; Hudson, Elek, \& Fleck, 2001; Johnston \& Mash, 1989; Landry, Smith, \& Swank, 2003; Priel \& Besser, 2000; Sanders \& Woolley, 2005). Parenting sense of competence is a construct derived from social-cognitive perspective (Bandura, 1982; Bandura \& Cervone, 1983), which emphasizes cognitive processes in the development of personality. However, in research and measurement of parenting cognitions about their parenting, there has been quite a lot of differences and overlap between constructs of parenting competence, self-efficacy, and parenting self-esteem. Authors sometimes use these terms interchangeably and, even when they do not, the definitions of parenting self-efficacy and competence are very similar (Vance \& Brandon, 2017). One of the reasons for this lack of conceptual clarity might stem from using different measurements and their theoretical backgrounds. While some studies focus on self-efficacy as one's perception of one's competency at performing different tasks, either in a task-specific (relating to specific tasks of parenting), domain-specific (relating to different tasks in a broader domain of parenting) or domain-general (a global competency expectation as a parent) (Boruszak-Kiziukiewicz \& Kmita, 2020; Coleman \& Hildebrandt Karraker, 2000; Wittkowski, Garrett, Calam, \& Weisberg, 2017), others take a broader approach to conceptualizing parenting competence (Miklósi, Szabó, \& Simon, 2017; Ohan, Leung, \& Johnston, 2000; Rybski \& Israel, 2017; Teti \& Gelfand, 1991). This approach 
defines parental sense of competence in terms of parental self-esteem in accordance with multidimensional models of self-esteem (Harter, 1985; Tafarodi \& Swann, 1995). This approach defines parenting competence as having two correlated but independent components-one referring to a sense of personal efficacy and one referring to a sense of one's value and satisfaction as a parent. Therefore, parents, who feel competent in their parenting role, consider themselves in control of their parenting behavior, efficient in their ability as a parent, and they are satisfied with themselves as a parent (Grusec, Hastings, \& Mammone, 1994; Miklósi et al., 2017; Ohan et al., 2000; Rybski \& Israel, 2017; Sanders \& Wooley, 2005; Sevigny \& Loutzenhiser, 2010).

Parenting sense of competence is an important focus of both research and interventions aimed at preventing or alleviating problems behaviors in children (Holden, 2010; Kapetanovic, Skoog, Bohlin, \& Gerdner, 2019; Latham, Mark, \& Oliver, 2018). This seems to be especially important if a child is at risk or has special needs, due to greater demands and pressures that parents are faced with (Baxter, Cummins, \& Yiolitis, 2000; Challela, 1981). Developmental disability in the family often affects the entire family system, usually because the mother has to provide extra care and time for the disabled child, leaving fewer resources for other responsibilities and relationships, within or outside the family (Lundy, 2011; Vanderkerken, Heyvaert, Onghena, \& Maes, 2019). Children with intellectual disability process information more slowly than children without intellectual disability. They have difficulties communicating, managing life skills, and understanding abstract concepts (Minnes, 1998; Shaffer et al., 1985). According to the fifth edition of Diagnostic and statistical manual of mental disorders (DSM-5; American Psychiatric Association [APA], 2013) diagnosis of intellectual disability is warranted when a child has a deficit in intellectual functioning (e.g., reasoning, problem solving, abstract thinking etc.), and significant impairment in adaptive functioning. As opposed to older classifications, namely International Statistical Classification of Diseases and Related Health Problems (ICD-10; World Health Organization, 2009) and DSM-IV (APA, 1994), the severity of the disability is determined on the basis of deficits in adaptive functioning in three domains (conceptual, social and practical), and not on the basis of intellectual impairment or IQ score. Children with mild intellectual disability have difficulties in acquiring academic skills (such as reading, writing, calculus) and abstract thinking as they get older (APA, 2013, 2019). Their level of social and practical functioning is below what is expected for their age group. They are usually able to develop satisfactory relationships and basic self-care, but they require support in certain areas (such as social reasoning or self-protection) (Alexander \& Reynolds, 2020; Platt, Keyes, McLaughlin, \& Kaufman, 2019). Children with moderate intellectual disability display significant delay in acquisition of academic skills and require constant support (APA, 2013, 2019; Sermier Dessemontet, de Chambrier, Martinet, Moser, \& Bayer, 2017). Similarly, their social functioning is characterized with significant deficits reading social cues and understanding relationships (APA, 2013, 2019; Platt et al., 2019), while in practical domain usually their competence is limited to basic self-care and requires a prolonged learning period (APA, 2013, 2019). Children with severe intellectual disability have very limited acquisition of academic skills, and limited understanding of written word. Their social functioning is severely limited in terms of vocabulary and syntax, and they require support and supervision in practically all everyday activities (APA, 2013, 2019).

Raising a child with intellectual disability brings a set of challenges for parents in terms of managing a growing need for care, availability of support and dealing with the child's limitations (Challela, 1981; Hastings \& Brown, 2002; Krauss, 1993; Salonen et al., 2009). Studies show that parents often feel fear, frustration, helplessness and guilt for not being able to help their child more (Baxter et al., 2000; Challela, 1981; Moos \& Holahan, 2003), all of which can result in them feeling incompetent as parents and consequently affect parenting practices and child's well-being. Parents who feel competent in their parenting tasks, on the other hand, are less likely to perceive their child as problematic, and more likely to be satisfied (Coleman \& Hildebrant Karraker, 2000). Even though parents of children with intellectual disability report being satisfied with their children and that having a child with intellectual disability has had a positive impact on their self-efficacy and satisfaction (Bunga, Manchala, Tondehal, \& Shankar, 2020; Gilmore \& Cuskelly, 2012; MacInnes \& Fraser, 2009), as well as personal growth, maturity and family life in general (Hastings, Allen, McDermott, \& Still, 2002), there are also studies demonstrating differences in comparison to parents of children without disability. For example, Al-Kandari and Al-Qashan (2010) found that mothers of children with intellectual disability had exhibited lower levels of self-efficacy and had negative beliefs about their parental abilities, while Gilmore and Cuskelly (2012) found that parents adapt to their child's needs over time, and their sense of competence, while lower at first, does increase as the child 
develops. Moreover, the effects on parental self-esteem do not necessarily come from the child's disability per se, but rather from associated behavioral and emotional problems (Ohan et al., 2000).

Therefore, the link between characteristics of the child with intellectual disability and parenting sense of competence is not yet clear, given that studies show different results. This suggest that there are other factors, which might determine parental adjustment to their child's disability and their sense of competence as a parent, apart from the disability itself. Indeed, studies suggest that there are socio-economic factors which might have a significant role (DeLongis \& Holtzman, 2005; Jones \& Prinz, 2005). Flynt and Wood (1989) demonstrated the effects of age, marital and socio-economic status on coping and adjustment of mothers of children with moderate intellectual disability. Employment status is related to better socio-economic status and thus has positive effects in terms of stress reduction (Cidav, Marcus, \& Mandell, 2012; Saltzstein et al., 2001). However, in parents of children with intellectual disability, one parent is often unemployed due to increased need for care (either by choice or due to getting fired which is often the case in Croatia), which can put an extra strain on families' resources, increase stress and affect adjustment. Studies in both Eastern and Western countries have shown that mothers of children with disabilities are unemployed more often than mothers of children without disabilities (Brown \& Clark, 2017; Ejiri \& Matsuzawa, 2019; Olsson \& Hwang, 2006). Although a variety of factors affect employment status of parents of children with or without disability (Brown \& Clark, 2017), data consistently shows that child's disability is one of the factors associated with it. Also, Ouyang et al. (2014) found that parent of children with fragile X syndrome and parents of children with autism spectrum disorders and intellectual disability have more often quit their job or worked less in order to take care of the child, than parents of children with either autism spectrum disorder or intellectual disability. Similar differences were found by Saunders et al. (2015). These results suggest that a more severe disability is related to more unemployment and financial burden.

Education, on the other hand, was shown to be an important factor in parental adjustment to their child's disability, mostly due to more knowledge, better understanding of the disability and more proactive attitudes and self-advocacy (Landry, Smith, \& Swank, 2006; Miller, Gordon, Daniele, \& Diller, 1992). Number of children in the family could affect parenting sense of competence in different ways. On one hand, previous experience in raising children has shown positive effects on parenting and family adjustment (Glidden, Flaherty, \& McGlone, 2000). On the other hand, having more children, especially young ones close in age, can put an extra strain on parents, both financially and emotionally, as some studies suggest (Kwai-sang Yau \& Li-Tsang, 1999; Skreden et al., 2012).

Finally, perceived stress was shown to be a major factor in explaining parenting sense of competence, parental behavior as well as overall adjustment in both parents of children with disabilities and in parents of typical children (Johnston \& Mash, 1989; Panneton \& Deater Deckard, 2017). The relationship between stress and parenthood has long since been a subject of research in developmental psychology (Crnic, Greenberg, Ragozin, Robinson, \& Basham, 1983; Deater Deckard \& Scarr, 1996; Hastings \& Brown, 2002; Salonen et al., 2009). Research has mostly, focused on general sources of parenting stress, such as various social and economic factors (low income or unemployment), or child's intellectual disability (Conger \& Elder, 1994; Crnic et al., 1983; Demerouti et al., 2005; Whippl \& Webster-Stratton, 1991), which, when accumulated, can decrease parents' sense of efficacy and affect the quality of parent-child interactions (Crnic \& Low, 2002; Deater Deckard, 1998; Gutermuth et al., 2005; Reece \& Harkless, 1998). Indeed, studies show that daily stress is related to parenting behavior (Deater Deckard, 2005) and parenting competence (Deater Deckard, 1998). Studies also consistently show elevated levels of stress in parents of children with intellectual disability (Arakkathara \& Bance, 2019; MacInnes \& Fraser, 2009; Masulani-Mwale, Kauye, Gladstone, \& Mathanga, 2018; Phillips, Conners, \& Curtner-Smith, 2017; Tsermentseli \& Kouklari, 2019), both mothers (Leung, 2019) and fathers (Marsh, Brown, \& Mccann, 2020), although those levels are related solely to the child's disability but also other factors, both internal (such as parents' coping) end external (such as social support), as well as the child's internalizing and externalizing problems (Barak-Levy \& Atzaba-Poria, 2020; Hassall, Rose, \& McDonald, 2005; Leung, 2019). Higher levels of stress in parents of children with intellectual disability put a significant strain on parents, increase the risk of mental health problems, marital problems and can impair parents' ability to positively affect the child's behavior, as well as decrease wellbeing and overall quality of family life (Arakkathara \& Bance, 2019; Azeem et al., 2013; Barak-Levy \& Atzaba-Poria, 2020; Langley, Totsika, \& Hastings, 2020).

The focus of our study was to examine the effects of child's intellectual disability, socio-demographic variables, and perceived stress on parenting sense of competence (satisfaction and self-efficacy) in a sample of parents in Croatia. 


\section{Method}

\section{Participants and Procedure}

Participants were 107 parents of primary school children ( 79 mothers and 28 fathers), aged 28 to 57 years old $(M=41.86$, $S D=5.652)$. The unequal number of mothers and fathers is not unexpected given the fact that involvement in child's education as well as other childcare activities has been in favor of mothers, especially more traditional societies (Craig \& Mullan, 2011). Croatia is still quite traditional in its understanding of gender roles, with mothers assuming more responsibility in childcare (Bartolac \& Kamenov, 2013).

The majority of participants were married or in a civil union $(89.7 \%)$, while $10.3 \%$ were divorced or widowed. The majority of parent had two or three children (77.5\%), $13.1 \%$ had only one child, and $9.3 \%$ had more than three children. More than half of the participants (54.7\%) have a high-school degree, $8.4 \%$ had primary school education, while $36.8 \%$ of the participants had a higher education degree (university or postgraduate studies). With regard to the employment, $67.9 \%$ of the participants were employed and $32.1 \%$ of them were unemployed or retired (there were no parents with part time employment).

There were three groups of parents; parents of children without intellectual disability $(N=35,32.7 \%)$, parents of children with mild intellectual disability $(N=33,30.85 \%)$, and parents of children with moderate/severe intellectual disability $(N=39,36.4 \%)$. In all three groups, children were 7 to 14 years of age, with equally distributed genders, 15 to 17 girls, and 16 to 22 boys respectively. The diagnosis of intellectual disability was made independent of the study by an interdisciplinary team comprised of a psychiatrist a psychologist, an educational rehabilitator, a speech therapist, a pedagogist, a teacher and a school medicine specialists.

Inclusion criteria for mild intellectual disability group were: having children with diagnosed mild intellectual disability or borderline intellectual disability with comorbid specific developmental disorders (including but not limited to communication disorders, learning disorders, attention deficit hyperactivity disorder, or autism spectrum disorderseverity level 1) whose level of adaptive functioning is congruent with mild intellectual disability and require support in different domains of functioning. Inclusion criteria for moderate/severe group were: having children with diagnosed moderate or severe intellectual disability with or without comorbid severe developmental disorders (including but not limited to autism spectrum disorder-severity level 2 and 3, Rett syndrome, cerebral palsy). There were only five parents of children with diagnosed severe intellectual disability, and for that reason, the decision was made to merge parents of children with diagnosed mild and severe intellectual disability. Inclusion criteria for parents of children without intellectual disability was having a child without developmental disabilities. Additional inclusion criteria for all three groups of parents was giving informed, written consent for participation in the study. Exclusion criteria was having a child with serious psychiatric comorbidity (e.g., psychosis) and not providing informed, written consent. Inclusion and exclusion were made based on children' medical record documentation.

The study was approved by institutional Ethics committee, and conducted in one elementary school and one special education institution in Croatia. Subsamples of parents of children without intellectual disability and parents of children with mild intellectual disability were examined in the elementary school where their children were enrolled, while subsample of parents of children with moderate/severe intellectual disability was examined in the special education institution were their children were enrolled.

Parents completed measures of parenting sense of competence, perceived stress and socio-demographic questions during group parent-teacher meetings. Participation was voluntary, written consent was obtained and participant were informed of the anonymity and the confidentiality of obtained data, as well as that they can terminate their involvement in the study at any time.

\section{Measures}

Socio-demographic data were collected on age, gender, number of children, marital status, educational level and parental employment. 


\section{Parenting Sense of Competence Scale}

Parenting sense of competence was measured using Parenting Sense of Competence Scale (PSOC; Gibaud-Wallston \& Wandersman, 1978), translation by Gustović-Ercegovac (1992). It is a 17 item self-report measure of parenting satisfaction (9 items, e.g., "My talents and interests are in other areas, not in being a parent") and self-efficacy (8 items, e.g., "I honestly believe I have the skills necessary to be a good mother/father to my child"). Participant are expected to judge their agreement with items regarding their experience as a parent on a 6-point scale (ranging from 1-strongly disagree to 6-strongly agree). Higher scores indicate higher satisfaction and self-efficacy. The scale has good internal consistency with coefficients ranging from .77 to .80 (Ohan et al., 2000). Cronbach alpha coefficients in our study were .71 for parenting satisfaction and .70 for self-efficacy for the entire sample. Reliability coefficients for parents of children without intellectual disability were .77 for parenting satisfaction and .83 for self-efficacy. Reliability coefficients for parents of children with mild intellectual disability were .79 for parenting satisfaction and .85 for self-efficacy. Reliability coefficients for parents of children with moderate/severe intellectual disability were .82 for parenting satisfaction and .91 for self-efficacy.

\section{Perceived Stress}

Perceived stress was measured using the Perceived Stress Scale-10 (PSS; Cohen, Kamarck, \& Mermelstein, 1983), translation by Hudek-Knežević, Kardum, and Lesić (1999). PSS-10 is a 10 item self-report scale measuring the level of experienced stress during the previous month. Participants are expected to answer how often they experienced each sensation on a 5-point scale (ranging from 0-never to 4-very often). Higher scores indicate higher levels of perceived stress. The scale has shown good reliability both in English and Croatian with reliability coefficients ranging from .78 (Cohen et al., 1983) to .88 (Hudek-Knežević et al., 1999). Cronbach alpha in our study was .88 for the entire sample, .84 for parents of children without intellectual disability, .87 for parents of children with mild intellectual disability, and .83 for parents of children with moderate/severe intellectual disability.

\section{Results}

Table 1 shows descriptive data for parenting satisfaction, self-efficacy, and perceived stress for the entire sample, while Table 2 shows descriptive data for parenting satisfaction, self-efficacy, and perceived stress across three groups of parents.

Table 1

Descriptive Data for Parenting Satisfaction, Parenting Self-Efficacy and Perceived Stress

\begin{tabular}{lcccc}
\hline Variable & $\boldsymbol{M}$ & $\boldsymbol{S D}$ & Observed range & Possible range \\
\hline Parenting satisfaction & 40.39 & 9.008 & $9-54$ & $9-54$ \\
Parenting self-efficacy & 35.10 & 6.920 & $14-48$ & $8-48$ \\
Perceived stress & 17.09 & 5.997 & $3-31$ & $0-40$ \\
\hline
\end{tabular}

Table 2

Descriptive Data for Parenting Competence and Perceived Stress Across Three Groups of Parents

\begin{tabular}{|c|c|c|c|c|c|c|c|c|c|}
\hline \multirow[b]{2}{*}{ Variable } & \multicolumn{3}{|c|}{$\begin{array}{c}\text { Parents of children without } \\
\text { intellectual impairment }(N=35)\end{array}$} & \multicolumn{3}{|c|}{$\begin{array}{l}\text { Parents of children with mild } \\
\text { intellectual impairment }(N=33)\end{array}$} & \multicolumn{3}{|c|}{$\begin{array}{l}\text { Parents of children with severe } \\
\text { intellectual impairment }(N=39)\end{array}$} \\
\hline & $M$ & $S D$ & Min-Max & $M$ & $S D$ & Min-Max & $M$ & $S D$ & $\operatorname{Min}-\operatorname{Max}$ \\
\hline Parenting satisfaction & 44.00 & 6.22 & $32-52$ & 39.52 & 8.40 & $22-54$ & 37.60 & 10.77 & $9-54$ \\
\hline Parenting self-efficacy & 35.60 & 6.09 & $22-47$ & 34.72 & 7.07 & $23-48$ & 34.97 & 7.67 & $14-48$ \\
\hline Perceived stress & 15.06 & 5.06 & $4-27$ & 18.30 & 7.07 & $3-31$ & 17.92 & 5.48 & $3-26$ \\
\hline
\end{tabular}


As can be seen in both Table 1, descriptive data point to parents exhibiting moderate to high sense of parenting satisfaction and self-efficacy, and moderate levels of perceived stress. However, standard deviations and observed range suggest that parents differ in their perception of parenting competence and stress almost across the entire theoretical range (especially for parenting competence).

Similarly to the results for the entire sample, parents exhibiting moderate to high sense of parenting satisfaction and self-efficacy, and moderate levels of perceived stress, but measures of dispersion suggest that parents differ in their perception of parenting competence and stress.

In order to examine the relationship between child's intellectual disability socio-demographic variables, perceived stress and parenting satisfaction and self-efficacy correlation analysis was performed. Socio-demographic variables were coded as follows; Gender: 1-male, 2-female; Marital status: 1-marriage/civil union, 2-widowed/divorced (there were no single parents); Parents' education level: 1-primary school, 2-high school, 3-university/postgraduate, and parental employment: 1-yes, 2-no (there were no parents with part-time employment nor retired parents). According to child's intellectual disability, groups of parents were coded as follows: 1-parents of children without intellectual disability, 2-parents of children with mild intellectual disability, and 3-parents of children with moderate/severe intellectual disability. In accordance with requirements for correlations between variables, we used point-biserial coefficient to test correlation of gender, parental employment and marital status with criterion variables (parenting satisfaction and self-efficacy), Spearman's coefficient to test correlation of parents' age, education level and child's disability with criterion variables, and Pearson's coefficient to test the correlation between Perceived stress and criterion variables. The results are presented in Table 3.

Table 3

Correlation Coefficients Between Observed Variables

\begin{tabular}{|c|c|c|c|c|c|c|c|c|c|}
\hline Variable & 1 & 2 & 3 & 4 & 5 & 6 & 7 & 8 & 9 \\
\hline 1. Parents' gender & - & & & & & & & & \\
\hline 2. Parents' age & $-.20^{*}$ & - & & & & & & & \\
\hline 3. Number of children & -.11 & $.32^{* *}$ & - & & & & & & \\
\hline 4. Marital status & .13 & -.11 & .02 & - & & & & & \\
\hline 5. Parents' education level & -.16 & .11 & $-.35^{* *}$ & -.15 & - & & & & \\
\hline 6. Parental employment & .05 & .04 & -.08 & .10 & $-.24^{*}$ & - & & & \\
\hline 7. Child's disability & .06 & -.14 & .00 & $.05^{*}$ & $-.21^{* \star *}$ & $-.28^{* *}$ & - & & \\
\hline 8. Perceived stress & -.07 & .07 & .04 & .16 & -.00 & .12 & $.19^{*}$ & - & \\
\hline 9. Parenting self-efficacy & -.13 & -.16 & .13 & -.02 & $-.24^{*}$ & .13 & -.12 & $-.29^{* * *}$ & - \\
\hline 10. Parenting satisfaction & .06 & -.14 & .00 & -.05 & $.21 *$ & $-.28^{* * *}$ & $-.37^{* *}$ & $-.53^{* * *}$ & .15 \\
\hline
\end{tabular}

As shown in Table 2, parenting satisfaction is negatively correlated with perceived stress, $r(107)=-.53$, $p<.01$, and parental employment, $r(107)=-.28, p<.01$, and positively correlated with parents' education level, $r(107)=.21, p<.05$. Therefore, parents who perceive more stress, who are employed, and parents with higher education level, are also more satisfied with their parenting role. Parenting satisfaction is also negatively correlated with child's disability, $r(107)=$ $-.37, p<.01$. Parenting self-efficacy correlated significantly (negatively) with perceived stress, $r(107)=-.29, p<.01$, and parents' educational level, $r(107)=-.24, p<.05$, but was not significantly correlated with child's disability. In other words, parents who perceive more stress and have a higher educational level, feel less efficient in their parenting role. Other socio-demographic variables did not correlate significantly with parenting satisfaction nor self-efficacy. It is important to point to the fact that parents' gender did not have significant correlations with either variable except parents' age, which suggest that the unequal number of mothers and fathers in the sample most likely would not affect the results. 
In order to examine the effects of child's disability, socio-demographic variables and perceived stress on parenting satisfaction and efficacy, hierarchical regression analyses were performed. Child's disability was entered in the first step, parent's educational level and parental employment in the second, and perceived stress in the third step. Results are presented in Table 4 and Table 5.

\section{Table 4}

Results of Hierarchical Regression Analyses for Parenting Satisfaction

\begin{tabular}{lll}
\hline Predictor & \multicolumn{1}{c}{$\boldsymbol{\beta}$} & Summary \\
\hline Step 1 & & $R^{2}=.08^{* *}, F=10.25^{* *}$ \\
$\quad$ Child's disability & $-0.30^{* *}$ & \\
Step 2 & & $R^{2}=.11(p=.05), \Delta R^{2}=.03(p=.05), F=5.08^{* *}$ \\
$\quad$ Child's disability & -0.10 & \\
$\quad$ Parents' education level & 0.12 & \\
$\quad$ Parental employment & $-0.21^{*}$ & \\
Step 3 & & \\
$\quad$ Child's disability & $0.49^{* * *}=.33^{* * *}, \Delta R^{2}=.22^{* * *}, F=13.63^{* * *}$ \\
$\quad$ Parents' education level & 0.12 & \\
Parental employment & -0.16 & \\
Perceived stress & $-0.49^{* * *}$ & \\
${ }^{*} p<.05 .{ }^{* *} p<.01 .{ }^{* * *} p<.001$. & &
\end{tabular}

\section{Table 5}

Results of Hierarchical Regression Analyses for Parenting Self-Efficacy

\begin{tabular}{lll}
\hline Predictor & $\boldsymbol{\beta}$ & Summary \\
\hline Step 1 & 0.01 & $R^{2}=.01, F=0.02$ \\
$\quad$ Child's disability & & $R^{2}=.06^{*}, \Delta R^{2}=05^{*}, F=3.07^{*}$ \\
Step 2 & $0.30^{*}$ & \\
$\quad$ Child's disability & $-0.31^{* *}$ & \\
$\quad$ Parents' education level & -0.11 & \\
$\quad$ Parental employment & & \\
Step 3 & 0.06 & \\
$\quad$ Child's disability & -0.31 & \\
$\quad$ Parents' education level & -0.15 & \\
Parental employment & $-0.34^{* *}$ & \\
Perceived stress & & \\
${ }^{*} p<.05^{* *} p<.01{ }^{* * *} p<.001$ &
\end{tabular}

${ }^{*} p<.05 .{ }^{* *} p<.01 .{ }^{* * *} p<.001$.

As can be seen in Table 4, child's disability predicted parenting satisfaction in a sense that higher disability severity predicted lower satisfaction. Parents' education level did not have significant effects, but parental employment predicted higher satisfaction. However, once parents' education level and parental employment were entered in the equation, child's disability was no longer significant, suggesting that child's disability predicts lower parenting satisfaction because it predicts unemployment, which is further supported by positive, significant correlation between child's disability and parental employment (see Table 2). Finally, perceived stress, in the third step, predicted lower parenting satisfaction. However, once perceived stress was entered in the equation, the effect of child's disability became significant again, higher and of an opposite direction, while the effect of unemployment was no longer significant. Given the fact that perceived stress and employment were not significantly related, this suggest that there might be an interaction between 
child's disability and parental employment affecting perceived stress, as well as parenting satisfaction. The model explained $33 \%$ of total variance of parenting satisfaction.

As shown in Table 5, child's disability was not a significant predictor. However, once parental employment and parents' education level were entered the hierarchical regression analysis (HRA), child's intellectual disability (positively) and parents' education level (negatively) were both significant predictors, which was not in accordance with correlational analysis. Correlations between child's disability, parents' education level and parental employment most likely led to the inflation of variance in the second step (suppression effect). Perceived stress, in the final step, contributed significantly to parenting self-efficacy in a negative direction. The model explained $17 \%$ of total variance of parenting satisfaction.

Due to changes in beta coefficients depending on variables entered in individual step of the HRA, which suggested interactions between child's disability and parental employment we performed moderation analyses using Hayes' (2009) process macro for parenting satisfaction and self-efficacy, as well as perceived stress. The results of the analyses are shown in Table 6.

Table 6

Results of Hayes' Process for Simple Moderation Analyses

\begin{tabular}{|c|c|c|c|c|}
\hline Predictor & Coefficient & $t$ & $p$ & $95 \% \mathrm{CI}$ \\
\hline \multicolumn{5}{|l|}{ Parenting satisfaction } \\
\hline Child's disability & -5.6623 & -2.5010 & .0140 & {$[-10.1550,-1.1695]$} \\
\hline Parental employment & 3.4467 & 1.7056 & .0912 & {$[-0.5635,7.4570]$} \\
\hline Interaction & 4.9158 & 2.2646 & .0264 & {$[0.5482,7.3589]$} \\
\hline \multicolumn{5}{|l|}{ Parenting self-efficacy } \\
\hline Child's disability & -0.9330 & -0.5351 & .5938 & {$[-4.3942,2.5282]$} \\
\hline Parental employment & -2.2802 & -1.4029 & .1639 & {$[-5.5066,0.9461]$} \\
\hline Interaction & 0.4922 & 0.2474 & .8051 & {$[-3.4567,4.4411]$} \\
\hline \multicolumn{5}{|l|}{ Perceived stress } \\
\hline Child's disability & 3.0139 & 3.0326 & .0031 & {$[1.0417,4.9861]$} \\
\hline Parental employment & -0.4985 & -0.4066 & .6852 & {$[-2.9310,1.9340]$} \\
\hline Interaction & -2.5101 & -1.9999 & .0252 & {$[-5.0008,-0.0194]$} \\
\hline
\end{tabular}

As can be seen in Table 6, the interaction effects of child's disability and parental employment on parenting satisfaction and perceived stress were significant, while no significant effect was found regarding parenting self-efficacy. Analyses of conditional effects showed that the interactions were significant only in unemployed parents. In order to better understand the interactions, they are presented in Figures 1 and 2. 
Figure 1

Effect of Interaction Between Child's Disability and Parental Employment on Parenting Satisfaction

\section{Parenting satisfaction}

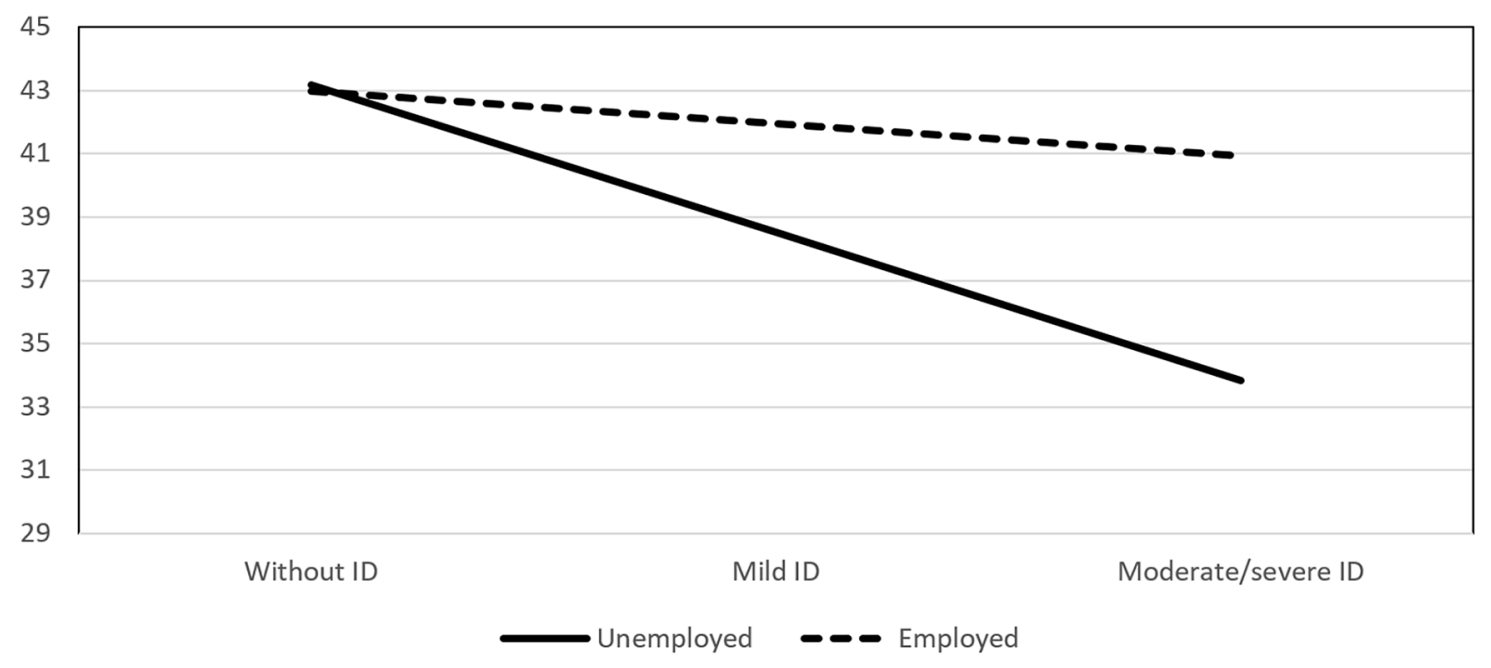

Figure 2

Effect of Interaction Between Child's Disability and Parental Employment on Perceived Stress

\section{Perceived stress}

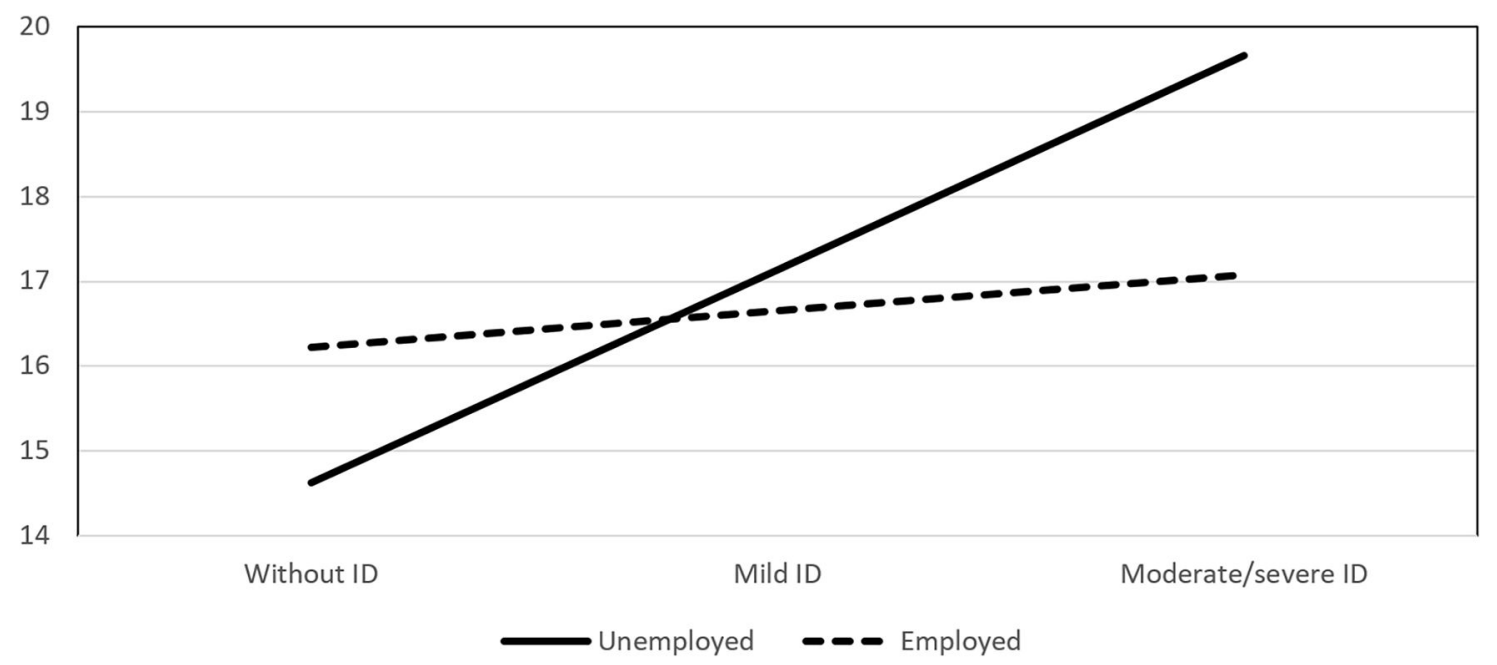

As can be seen in Figure 1, parents of children without intellectual disability do not differ in their satisfaction with respect to employment, while parents of children with intellectual disability do. The most pronounced difference is between employed and unemployed parents of children with moderate/severe intellectual disability. The unemployed parents are significantly less satisfied than the employed ones. Therefore, the differences are significant only in unemployed parents, suggesting a cumulative negative effect of unemployment and child's disability on parental satisfaction.

As can be seen in Figure 2, unemployed parents of children with moderate/severe intellectual disability experience more stress that the employed ones, while the opposite is the case in parent of children with mild intellectual disability. 
The differences are also significant only in unemployed parents, suggesting that unemployment significantly increases stress in parents of children with moderate/severe intellectual disability.

\section{Discussion}

Given the fact that, for most parents, satisfaction that they feel in their role as a parent greatly determines their satisfaction with life, the perception of competence as a parent is of vital importance for personal adjustment of the parents and their children (Arakkathara \& Bance, 2019; Bunga et al., 2020; Langley et al., 2020), especially in parents of children with intellectual disability (Azeem et al., 2013; Lundy, 2011; Masulani-Mwale et al., 2018). With that in mind, our study has focused on examining the effects of the child's intellectual disability on parenting sense of competence, as well as factors that might explain those effects.

Descriptive analysis has shown that, on average, parents feel satisfied and efficient in their parenting role. Although there were differences in parenting satisfaction between parents, as demonstrated by the range of the results, most parents feel confident about their knowledge, skills and abilities and find parenthood enjoyable and fulfilling. Descriptive data for perceived stress suggests that the majority of parents experience moderate levels of stress, although the range of results suggest that parent differ in their experience of stress.

Certain degree of concern about child behavior and development is an inevitable part of parenting (Hastings \& Brown, 2002; Salonen et al., 2009). While those concerns may stem from parents' sensitivity to their child's needs and motivate parents to meet those needs, they may also significantly increase stress if parents perceive that they cannot meet them (Deater Deckard, 2005).

Results of correlational analysis have shown correlations of child's intellectual disability with parenting satisfaction, while it had no significant relations with parenting self-efficacy. Parents whose children have intellectual disability often encounter situations in which they feel helpless, frustrated and incompetent (Barak-Levy \& Atzaba-Poria, 2020; Challela, 1981; Walden, Pistrang, \& Joyce, 2000). In terms of developmental milestones, parents expect a child to be able to acquire new skills and competencies. Unfortunately, those expectations usually need to be changed and adapted, especially when it comes to children with intellectual disability whose parents often have trouble accepting their child's limitations (Marsh et al., 2020). Continuous feelings of frustration and disappointment can lead parents to feel less satisfied with themselves as parents. Parenting self-efficacy, on the other hand, is more related to parents' skills than child's characteristics. Parents who feel efficient feel that they can solve problems related to their child and influence their behavior. It is less correlated with expectations from the child and more correlated with expectations from oneself, therefore understandably not correlated with the child's disability (Jones \& Prinz, 2005; Vance \& Brandon, 2017).

Regarding socio-demographic factors, our results did not show significant relations between parents' education level or parental employment, and perceived stress or parenting self-efficacy, but they did show that unemployed parents and less educated parents are less satisfied in their parenting role. This is in line with studies demonstrating positive effects of education on satisfaction with oneself, one's life as well as parenting (Craig, 2006; Melin, Fugl-Meyer, \& Fugl-Meyer, 2003; Orth, Trzesniewski, \& Robins, 2010), and can also be indicative of economic pressures and parents feeling unable to sufficiently fulfil their child's needs. Finally, parenting sense of self-efficacy has shown a negative correlation with perceived stress, which is consistent with earlier findings (Hanson, McLanahan, \& Thomson, 1997; Masulani-Mwale et al., 2018; Tsermentseli \& Kouklari, 2019) where parents with higher levels of stress estimated themselves to be less efficient parents.

Results of hierarchical regression analyses were in line with correlational analysis, for the most part. The only significant predictor of parenting self-efficacy was perceived stress, while, child's disability, parental employment and perceives stress predicted satisfaction. The results are in line with previous studies demonstrating a negative relation of stress with parenting competence (Crnic \& Low, 2002). Furthermore, they are in line with studies showing that long-lasting low-intensity stress (i. e. chronic daily stress) has a stronger effect on adjustment than major life stressors (Asselmann, Wittchen, Lieb, \& Beesdo-Baum, 2017; Reece \& Harkless, 1998), because Perceived stress scale used in our study is saturated more with day-to-day stress rather than with effects of major life events. Research has demonstrated that stress affects self-confidence, self-competence and self-esteem (Hudd et al., 2000; Johnston \& Mash, 1989; Lazarus, 
2000; Lazarus \& Folkman, 1987, 2004; Reece \& Harkless, 1998). Similarly, parents, who feel overwhelmed or not in control of their lives, are likely not to feel very satisfied with themselves as parent as well as in other areas of life (Abidin, 1992), and are likely to be less responsive to their child's needs, which decreases their parenting sense of competence (Chavira, Wittchen, Lieb, \& Beesdo-Baum, 2000; Miller et al., 1992; Rybski \& Israel, 2017; Zukosky, 2009). Furthermore, our results suggest that stress has a weaker effect on parenting self-efficacy than it does on satisfaction. It is possible that even if a parent feels under stress, he or she still has to deal with obstacles and challenges of daily life, therefore may have the experience of successful coping and preserve a sense of self-efficacy. However, our result do suggest that the effects of stress on parenting competence are more emotional in nature, given the fact that parenting satisfaction reflects emotional experience of parenting, rather than a cognitive interpretation of ones skills and competence.

Finally, moderation analyses revealed effects of interaction between child's intellectual disability and parental employment on parenting satisfaction and perceived stress. With regard to parenting satisfaction, parents of children without intellectual disability were the most satisfied with their parental role, regardless of their employment, while parents of children with moderate/severe intellectual disability who were unemployed were less satisfied than employed ones. Apart from the added economic burden of unemployment, which could explain the difference, it is also possible that unemployed parents are too immersed in their child's life and lack balance in their own lives in terms of other sources of pleasure and satisfaction. Also, employed parents, due to better resources, could provide their child with extra help, as well as hire someone to help with everyday responsibilities, which can reduce stress and caregiver strain, as well as enable a parent to dedicate more quality time to their child, thus improving satisfaction. In support of that assumption, interaction of child's intellectual disability and parental employment showed significant effect on perceived stress as well. Unemployed parents of children with moderate/severe intellectual disability experience significantly more stress than employed parents, while the opposite was true in parents of children without intellectual disability. Taken together, these results suggest a protective role of employment, at least in parents of children with moderate/severe intellectual disability. Similar results were found by Brown and Clark (2017), and Morris (2012) who's results suggest that working mothers of school-aged children with disabilities have better work-family balance and mental health, as well as lower stress experience than unemployed mothers.

Our study offers some useful insights into the effects of child's intellectual disability on parenting satisfaction and perceived stress in parents. First, they suggest that parents of children with intellectual disability could benefit from interventions aimed at promoting their sense of satisfaction in their parental role. Given the fact that satisfaction is a very subjective outcome, interventions should focus on providing support in dealing with emotional consequences of their child having an intellectual disability, accepting the reality of the disability while not overprotecting the child and trying to compensate for things that are not under their control. In dealing with emotional consequences, parents could also benefit from re-examining their expectations from themselves and others in order to have a more realistic view of whether they are actually providing their child with everything that is in their power to provide, as well as differentiating between what is under their control and what is not. Given the fact that our results suggest that greater perceived stress negatively affects parenting satisfaction and self-efficacy, interventions aimed at managing stress, such as coping skills training, relaxation techniques as well as support groups could, also, prove to be useful.

Improving availability of information about intellectual disability per se, as well as about different options and adaptations (through workshops, informal education etc.) could reduce stress and make parent feel more in control of what happens to their child. Unfortunately, in Croatia, in the region where the study was conducted, there are few services available to children with disabilities, especially in rural areas, and virtually none, which provide support to parents.

Furthermore, our results have implications for policy makers, primarily regarding employment. Our result show that unemployed parents of children with moderate/severe intellectual disability are under greater stress and less satisfied with themselves as parents. Measures that encourage employment of parents with children with developmental disabilities and discourage illegal, but nevertheless present, practice of discriminating against parents (especially mothers) who have children with disabilities should be taken, as well as promoting more flexibility in the work place which might improve work-family balance, even when their child requires more support. 
Some limitations of our study should be mentioned. First, correlational and cross-sectional nature of the design prevents us from making causal conclusions as well as conclusions about whether the child's intellectual disability, parental employment or perceived stress temporally precede changes in parenting competence. Parenting competence and perceived stress were measured using self-report measures, which can be confounded by socially desirable responses, especially when it comes to parental satisfaction, which is a sensitive subject for most parents and it is likely that parents would be less likely to report being dissatisfied in their parental role. Small sample size could also be an issue in limiting the possibility of generalization of result. Even though disproportion of mothers and fathers in the sample most likely did not affect the results, future studies should include more fathers in order to examine the role of parents' gender.

Funding: The authors have no funding to report.

Acknowledgments: The authors have no additional (i.e., non-financial) support to report.

Competing Interests: The authors have declared that no competing interests exist.

\section{References}

Abidin, R. R. (1992). The determinants of parenting behavior. Journal of Clinical Child Psychology, 21(4), 407-412. https://doi.org/10.1207/s15374424jccp2104_12

Alexander, R. M., \& Reynolds, M. R. (2020). Intelligence and adaptive behavior: A meta-analysis. School Psychology Review, 49(2), 85-110. https://doi.org/10.1080/2372966X.2020.1717374

Al-Kandari, H. Y., \& Al-Qashan, H. (2010). Maternal self-efficacy of mothers of children with intellectual developmental disabilities, Down syndrome, and autism in Kuwait. Child and Adolescent Social Work fournal, 27, 21-39. https://doi.org/10.1007/s10560-009-0189-6

American Psychiatric Association. (1994). Diagnostic and statistical manual of mental disorders (4th ed.). Washington, DC, USA: American Psychiatric Press.

American Psychiatric Association. (2013). Diagnostic and statistical manual of mental disorders (5th ed.). Arlington, VA : Author. https://doi.org/10.1176/appi.books.9780890425596

American Psychiatric Association. (2019). Text change to the diagnostic features section of intellectual disability (intellectual developmental disorder). Retrieved from https://www.psychiatry.org/psychiatrists/practice/dsm/proposed-changes

Arakkathara, J. G., \& Bance, L. O. (2019). Promotion of well-being, resilience and stress management (POWER): An intervention program for mothers of children with intellectual disability: A pilot study. Indian fournal of Positive Psychology, 10(4), $294-299$.

Asselmann, E., Wittchen, H.-U., Lieb, R., \& Beesdo-Baum, K. (2017). A 10-year prospective-longitudinal study of daily hassles and incident psychopathology among adolescents and young adults: Interactions with gender, perceived coping efficacy, and negative life events. Social Psychiatry and Psychiatric Epidemiology, 52, 1353-1362. https://doi.org/10.1007/s00127-017-1436-3

Azeem, M. W., Dogar, I. A., Shah, S., Cheema, M. A., Asmat, A., Akbar, M., ... Haider, I. I. (2013). Anxiety and depression among parents of children with intellectual disability in Pakistan. fournal of the Canadian Academy of Child and Adolescent Psychiatry, 22(4), 290-295.

Bandura, A. (1982). Self-efficacy mechanism in human agency. American Psychologist, 37(2), 122-147. https://doi.org/10.1037/0003-066X.37.2.122

Bandura, A., \& Cervone, D. (1983). Self-evaluative and self-efficacy mechanisms governing the motivational effects of goal systems. Fournal of Personality and Social Psychology, 45(5), 1017-1028. https://doi.org/10.1037/0022-3514.45.5.1017

Barak-Levy, Y., \& Atzaba-Poria, N. (2020). A mediation model of parental stress, parenting, and risk factors in families having children with mild intellectual disability. Research in Developmental Disabilities, 98, Article 103577 https://doi.org/10.1016/j.ridd.2020.103577

Bartolac, A., \& Kamenov, Ž. (2013). Perceived distribution of family obligations between partners and perception of equity in a relationship. Sociology and Space-fournal for Spatial and Socio-Cultural Development Studies, 51(1), 67-90.

https://doi.org/10.5673/sip.51.1.4 
Baxter, C., Cummins, R. A., \& Yiolitis, L. (2000). Parental stress attributed to family members with and without disability: A longitudinal study. Journal of Intellectual and Developmental Disability, 25(2), 105-118. https://doi.org/10.1080/13269780050033526

Boruszak-Kiziukiewicz, J., \& Kmita, G. (2020). Parenting self-efficacy in immigrant families-A systematic review. Frontiers in Psychology, 11, Article 985. https://doi.org/10.3389/fpsyg.2020.00985

Brown, T. J., \& Clark, C. (2017). Employed parents of children with disabilities and work family life balance: A literature review. Child Youth Care Forum 46, 857-876. https://doi.org/10.1007/s10566-017-9407-0

Bunga, D., Manchala, H. G., Tondehal, N., \& Shankar, U. (2020). Children with intellectual disability, impact on caregivers: A crosssectional study. Indian fournal of Social Psychiatry, 36(2), Article 151. https://doi.org/10.4103/ijsp.ijsp_81_19

Chavira, V., Lopez, S. R., Blacher, J., \& Shapiro, J. (2000). Latina mothers' attributions, emotions, and reactions to the problem behaviors of their children with developmental disabilities. Journal of Child Psychology and Psychiatry, 41(2), 245-252. https://doi.org/10.1111/1469-7610.00605

Coleman, P., \& Hildebrandt Karraker, K. (2000). Parenting self-efficacy among mothers of school-age children: Conceptualization, measurement, and correlates. Family Relations, 49(1), 13-24. https://doi.org/10.1111/j.1741-3729.2000.00013.x

Coleman, P. K., \& Karraker, K. H. (1997). Self-efficacy and parenting quality: Findings and future applications. Developmental Review, 18(1), 47-85. https://doi.org/10.1006/drev.1997.0448

Craig, L. (2006). Parental education, time in paid work and time with children: An Australian time-diary analysis. The British fournal of Sociology, 57(4), 553-575. https://doi.org/10.1111/j.1468-4446.2006.00125.x

Craig, L., \& Mullan, K. (2011). How mothers and fathers share childcare: A cross-national time-use comparison. American Sociological Review, 76(6), 834-861. https://doi.org/10.1177/0003122411427673

Crnic, K. A., \& Low, C. (2002). Everyday stresses and parenting. In M. Bornstein (Ed.), Handbook of parenting (pp. 243-268). Hillsdale, NJ, USA: Erlbaum.

Crnic, K. A., Greenberg, M. T., Ragozin, A. S., Robinson, N. M., \& Basham, R. B. (1983). Effects of stress and social support on mothers of premature and full-term infants. Child Development, 54(1), 209-217. https://doi.org/10.2307/1129878

Challela, M. (1981). Helping parents cope with a profoundly mentally retarded child. In A. Milunsky (Ed.), Coping with crises and handicap (pp. 207-215). London, United Kingdom: Plenum Press.

Cidav, Z., Marcus, S. C., \& Mandell, D. S. (2012). Implications of childhood autism for parental employment and earnings. Pediatrics, 129(4), 617-623. https://doi.org/10.1542/peds.2011-2700

Cohen, S., Kamarck, T., \& Mermelstein, R. (1983). A global measure of perceived stress. Journal of Health and Social Behavior, 24(4), 385-396. https://doi.org/10.2307/2136404

Conger, R. D., \& Elder, G. H. (1994). Families in troubled times: Adapting to change in rural America. New York, NY, USA: Al-dine de Gruyter.

Deater Deckard, K. (1998). Parenting stress and child adjustment: Some old hypotheses and new questions. Clinical Psychology: Science and Practice, 5(3), 314-332. https://doi.org/10.1111/j.1468-2850.1998.tb00152.x

Deater Deckard, K. (2005). Parenting stress and children's development: Introduction to the special issue. Infant and Child Development, 14(2), 111-115. https://doi.org/10.1002/icd.383

Deater-Deckard, K., \& Scarr, S. (1996). Parenting stress among dual-earner mothers and fathers: Are there gender differences? fournal of Family Psychology, 10(1), 45-59. https://doi.org/10.1037/0893-3200.10.1.45

DeLongis, A., \& Holtzman, S. (2005). Coping in context: The role of stress, social support, and personality in coping. Journal of Personality, 73(6), 1633-1656. https://doi.org/10.1111/j.1467-6494.2005.00361.x

Demerouti, E., Bakker, A. B., \& Schaufeli, W. B. (2005). Spillover and crossover of exhaustion and life satisfaction among dual-earner parents. Fournal of Vocational Behavior, 67(2), 266-289. https://doi.org/10.1016/j.jvb.2004.07.001

Ejiri, K., \& Matsuzawa, A. (2019). Factors associated with employment of mothers caring for children with intellectual disabilities. International fournal of Developmental Disabilities, 65(4), 239-247. https://doi.org/10.1080/20473869.2017.1407862

Elek, S. M., Hudson, D. B., \& Bouffard, C. (2003). Marital and parenting satisfaction and infant care self-efficacy during the transition to parenthood: The effect of infant sex. Issues in Comprehensive Pediatric Nursing, 26(1), 45-57.

https://doi.org/10.1080/01460860390183065

Flynt, S. W., \& Wood, T. A. (1989). Stress and coping of mothers of children with moderate mental retardation. American fournal on Mental Retardation, 94, 278-283. 
Gibaud-Walston, J., \& Wandersman, L. P. (1978). Parenting sense of competence scale. In J. Touliatos, B. R. Perlmutter, \& G. W. Holden (Eds.), Handbook of family measurement techniques (pp. 166-167). Thousand Oaks, CA, USA: Sage Publications.

Gilmore, L. A., \& Cuskelly, M. (2008). Factor structure of the parenting sense of competence scale using a normative sample. Child Care, Health \& Development, 35(1), 48-55. https://doi.org/10.1111/j.1365-2214.2008.00867.x

Gilmore, L., \& Cuskelly, M. (2012). Parenting satisfaction and self-efficacy: A longitudinal study of mothers of children with Down syndrome. Journal of Family Studies, 18(1), 28-35. https://doi.org/10.5172/jfs.2012.1996

Glidden, L. M., Flaherty, E. M., \& McGlone, A. P. (2000). Is more too many? Adjustment in families with adopted children with developmental disabilities. Adoption Quarterly, 4(1), 67-80. https://doi.org/10.1300/J145v04n01_05

Greenspan, S. I., \& Wieder, S. (2003). The child with special needs: Encouraging intellectual and emotional growth. Lekenik, Croatia: Ostvarenje.

Grusec, J. E., Hastings, P., \& Mammone, N. (1994). Parenting cognitions and relationship schemas. In J. G. Smetana (Ed.), Beliefs about parenting: Origins and developmental implications (pp. 5-19). San Francisco, CA, USA: Jossey-Bass.

Gustović-Ercegovac, A. (1992). Prikaz skale percepcije kopetentnosti za roditeljsku ulogu. Defektologija, 28, 51-57.

Gutermuth, A. L., Anthony, B. J., Glanville, D. N., Naiman, D. Q., Waanders, C., \& Shaffer, S. (2005). The relationships between parenting stress, parenting behavior and preschoolers' social competence and behavior problems in the classroom. Infant and Child Development, 14(2), 133-154. https://doi.org/10.1002/icd.385

Hanson, T. L., McLanahan, S., \& Thomson, E. (1997). Economic resources, parental practices, and children's well-being. In G. J. Duncan \& J. Brooks-Gunn (Eds.), Con-sequences of growing up poor (pp. 190-238). New York, NY, USA: Russell Sage Foundation.

Harter, S. (1985). Competence as a dimension of self-evaluation: Toward a comprehensive model of self-worth. In R. Leagy (Ed.), The development of the self (pp. 55-118). New York, NY, USA: Academic Press.

Hassall, R., Rose, J., \& McDonald, J. (2005). Parenting stress in mothers of children with an intellectual disability: The effects of parental cognition in relation to child characteristics and family support. fournal of Intellectual Disability Research, 49(6), 405-418. https://doi.org/10.1111/j.1365-2788.2005.00673.x

Hastings, R., Allen, R., McDermott, K., \& Still, D. (2002). Factors related to positive perceptions in mothers of children with intellectual disabilities. Journal of Applied Research in Intellectual Disabilities, 15(3), 269-275. https://doi.org/10.1046/j.1468-3148.2002.00104.x

Hastings, R. P., \& Brown, T. (2002). Behavior problems of children with autism, parental self-efficacy, and mental health. American fournal on Mental Retardation, 107(3), 222-232. https://doi.org/10.1352/0895-8017(2002)107<0222:BPOCWA>2.0.CO;2

Hayes, A. F. (2009). Beyond Baron and Kenny: Statistical mediation analysis in the new millennium. Communication Monographs, 76(4), 408-420. https://doi.org/10.1080/03637750903310360

Holden, G. W. (2010). Parenting: A dynamic perspective (2nd ed.). London, United Kingdom: Sage Publications.

Hudd, S. S., Dumlao, J., Erdmann-Sager, D., Murray, D., Phan, E., Soukas, N., \& Yokozuka, N. (2000). Stress at college: Effects on health habits, health status and self-esteem. College Student fournal, 34, 217-227.

Hudek-Knežević, J., Kardum, I., \& Lesić, R. (1999). Effects of perceived stress and coping strategies on physical symptoms. fournal of General Social Issues, 8, 543-561.

Hudson, D. B., Elek, S. M., \& Fleck, M. O. (2001). First-time mothers' and fathers' transition to parenthood: Infant care self-efficacy, parenting satisfaction, and infant sex. Issues in Comprehensive Pediatric Nursing, 24(1), 31-43. https://doi.org/10.1080/014608601300035580

Johnston, C., \& Mash, E. J. (1989). A measures of parenting satisfaction and efficacy. fournal of Clinical Child Psychology, 18(2), 167-175. https://doi.org/10.1207/s15374424jccp1802_8

Jones, T. L., \& Prinz, R. J. (2005). Potential roles of parental self-efficacy in parent and child adjustment: A review. Clinical Psychology Review, 25(3), 341-363. https://doi.org/10.1016/j.cpr.2004.12.004

Kapetanovic, S., Skoog, T., Bohlin, M., \& Gerdner, A. (2019). Aspects of the parent-adolescent relationship and associations with adolescent risk behaviors over time. Fournal of Family Psychology, 33(1), 1-11. https://doi.org/10.1037/fam0000436

Krauss, M. W. (1993). Child-related and parenting stress: Similarities and differences between mothers and fathers of children with disabilities. American fournal on Mental Retardation, 97, 393-404.

Kwai-sang Yau, M., \& Li-Tsang, C. W. P. (1999). Adjustment and adaptation in parents of children with developmental disability in two-parent families: A review of the characteristics and attributes. The British fournal of Development Disabilities, 45(88), 38-51. https://doi.org/10.1179/096979599799156028 
Landry, S. H., Smith, K. E., \& Swank, P. R. (2003). The importance of parenting during early childhood for school-age development. Developmental Neuropsychology, 24(2-3), 559-591. https://doi.org/10.1080/87565641.2003.9651911

Landry, S. H., Smith, K. E., \& Swank, P. R. (2006). Responsive parenting: Establishing early foundations for social, communication, and independent problem-solving skills. Developmental Psychology, 42(4), 627-642. https://doi.org/10.1037/0012-1649.42.4.627

Langley, E., Totsika, V., \& Hastings, R. P. (2020). Psychological well-being of fathers with and without a child with intellectual disability: A population-based study. Journal of Intellectual Disability Research, 64(6), 399-413. https://doi.org/10.1111/jir.12692

Latham, R. M., Mark, K. M., \& Oliver, B. R. (2018). Coparenting and children's disruptive behavior: Interacting processes for parenting sense of competence. Journal of Family Psychology, 32(1), 151-156. https://doi.org/10.1037/fam0000362

Lazarus, R. S. (2000). Toward better research on stress and coping. American Psychologist, 55(6), 665-673. https://doi.org/10.1037/0003-066X.55.6.665

Lazarus, R. S., \& Folkman, S. (1987). Transactional theory and research on emotions and coping. European fournal of Personality, 1(3), 141-169. https://doi.org/10.1002/per.2410010304

Lazarus, R. S., \& Folkman, S. (2004). Stres, procjena i suočavanje. Jastrebarsko, Croatia: Naklada Slap.

Leung, P. (2019). Impact of fathers' support on marital satisfaction and caregiving straIn: Viewpoints of mothers of persons with intellectual disability in Hong Kong. Fournal of Policy and Practice in Intellectual Disabilities, 17(1), 51-58. https://doi.org/10.1111/jppi.12319

Lundy, H. F. (2011). Parental stress, socioeconomic status, satisfaction with services, and family quality of life among parents of children receiving special education services (Doctoral dissertation). Retrieved from https://scholarworks.gsu.edu/cgi/viewcontent.cgi? article $=1068 \&$ context $=$ cps_diss

Macinnes, L., \& Fraser, S. (2009). Parenting self-efficacy and stress in mothers and fathers of children with Down Syndrome. Retrieved from https://www.semanticscholar.org/paper/Parenting-self-efficacy-and-stress-in-mothers-and-MacInnes-LeMare/ c2f1fe13999056b13e490cf8c59e243750b9805c

Marsh, L., Brown, M., \& Mccann, E. (2020). The views and experiences of fathers of children with intellectual disabilities: A systematic review of the international evidence. Fournal of Policy and Practice in Intellectual Disabilities, 17(1), 79-90.

https://doi.org/10.1111/jppi.12328

Masulani-Mwale, C., Kauye, F., Gladstone, M., \& Mathanga, D. (2018). Prevalence of psychological distress among parents of children with intellectual disabilities in Malawi. BMC Psychiatry, 18, Article 146. https://doi.org/10.1186/s12888-018-1731-x

Melin, R., Fugl-Meyer, K. S., \& Fugl-Meyer, A. R. (2003). Life satisfaction in 18- to 64-year-old swedes: In relation to education, employment situation, health and physical activity. Journal of Rehabilitation Medicine, 35(2), 84-90. https://doi.org/10.1080/16501970306119

Miklósi, M., Szabó, M., \& Simon, L. (2017). The role of mindfulness in the relationship between perceived parenting, early maladaptive schemata and parental sense of competence. Mindfulness, 8, 471-480. https://doi.org/10.1007/s12671-016-0619-4

Miller, A. C., Gordon, R. M., Daniele, R. J., \& Diller, L. (1992). Stress, appraisal, and coping in mothers of disabled and nondisabled children. fournal of Pediatric Psychology, 17(5), 587-605. https://doi.org/10.1093/jpepsy/17.5.587

Minnes, P. (1998). Mental retardation: The impact upon the family. In J. A. Burack, R. M. Hodapp, \& E. Zigler (Eds.), Handbook of Mental Retardation and Development (pp. 693-712). New York, NY, USA: Cambridge University Press.

Moos, R. H., \& Holahan, C. J. (2003). Dispositional and contextual perspectives on coping: Toward an integrative framework. fournal of Clinical Psychology, 59(12), 1387-1403. https://doi.org/10.1002/jclp.10229

Morris, L. A. (2012). Testing respite effect of work on stress among mothers of children with special needs. fournal of Family and Economic Issues, 33, 24-40. https://doi.org/10.1007/s10834-011-9267-y

Ohan, J. L., Leung, D. W., \& Johnston, C. (2000). The parenting sense of competence scale: Evidence of a stable factor structure and validity. Canadian fournal of Behavioral Science, 32(4), 251-261. https://doi.org/10.1037/h0087122

Olsson, M. B., \& Hwang, C. P. (2006). Well-being, involvement in paid work and division of child-care in parents of children with intellectual disabilities in Sweden. fournal of Intellectual Disability Research, 50(12), 963-969.

https://doi.org/10.1111/j.1365-2788.2006.00930.x

Orth, U., Trzesniewski, K. H., \& Robins, R. W. (2010). Self-esteem development from young adulthood to old age: A cohort-sequential longitudinal study. Journal of Personality and Social Psychology, 98(4), 645-658. https://doi.org/10.1037/a0018769 
Ouyang, L., Grosse, S. D., Riley, C., Bolen, J., Bishop, E., Raspa, M., \& Bailey, D. B., Jr. (2014). A comparison of family financial and employment impacts of fragile X syndrome, autism spectrum disorders, and intellectual disability. Research in Developmental Disabilities, 35(7), 1518-1527. https://doi.org/10.1016/j.ridd.2014.04.009

Panneton, R., \& Deater-Deckard, K. (2017). Parental stress and early child development: Adaptive and maladaptive outcomes. Cham, Switzerland: Springer.

Phillips, B. A., Conners, F., \& Curtner-Smith, M. E. (2017). Parenting children with Down syndrome: An analysis of parenting styles, parenting dimensions, and parental stress. Research in Developmental Disabilities, 68, 9-19. https://doi.org/10.1016/j.ridd.2017.06.010

Platt, J. M., Keyes, K. M., McLaughlin, K. A., \& Kaufman, A. S. (2019). Intellectual disability and mental disorders in a US population representative sample of adolescents. Psychological Medicine, 49(6), 952-961. https://doi.org/10.1017/S0033291718001605

Priel, B., \& Besser, A. (2000). Dependency and self-criticism among first-time mothers: The roles of global and specific support. Journal of Social and Clinical Psychology, 19(4), 437-450. https://doi.org/10.1521/jscp.2000.19.4.437

Reece, S. M., \& Harkless, G. (1998). Self-efficacy, stress, and parental adaptation: Applications to the care of childbearing families. fournal of Family Nursing, 4(2), 198-215. https://doi.org/10.1177/107484079800400206

Rybski, D., \& Israel, H. (2017). Impact of social determinants on parent sense of competence in mothers experiencing homelessness or housed poverty. American fournal of Occupational Therapy, 33(4), 342-359. https://doi.org/7111505143p1.10.5014/ajot.2017.71S1-PO5153

Salonen, A. H., Kaunonen, M., Åstedt-Kurki, P., Järvenpää, A. L., Isoaho, H., \& Tarkka, M. T. (2009). Parenting self-efficacy after childbirth. Journal of Advanced Nursing, 65(11), 2324-2336. https://doi.org/10.1111/j.1365-2648.2009.05113.x

Saltzstein, A. L., Ting, Y., \& Hall Saltzstein, G. (2001). Work-family balance and job satisfaction: The impact of family-friendly policies on attitudes of federal government employees. Public Administration Review, 61(4), 452-467. https://doi.org/10.1111/0033-3352.00049

Sanders, M. R., \& Woolley, M. L. (2005). The relationship between maternal self-efficacy and parenting practices: Implications for parent training. Health \& Development, 31(1), 65-73. https://doi.org/10.1111/j.1365-2214.2005.00487.x

Saunders, B. S., Tilford, J. M., Fussell, J. J., Schulz, E. G., Casey, P. H., \& Kuo, D. Z. (2015). Financial and employment impact of intellectual disability on families of children with autism. Families, Systems \& Health: The fournal of Collaborative Family Healthcare, 33(1), 36-45. https://doi.org/10.1037/fsh0000102

Sermier Dessemontet, R., de Chambrier, A. F., Martinet, C., Moser, U., \& Bayer, N. (2017). Exploring phonological awareness skills in children with intellectual disability. American fournal of Intellectual Developmental Disabilities, 122(6), 476-491. https://doi.org/10.1352/1944-7558-122.6.476

Sevigny, P. R., \& Loutzenhiser, L. (2010). Predictors of parenting self-efficacy in mothers and fathers of toddlers. Child: Care, Health, Development, 36(2), 179-189. https://doi.org/10.1111/j.1365-2214.2009.00980.x

Shaffer, J., Friedrich, W. N., Shurtleff, D. B., \& Wolf, L. (1985). Cognitive and achievement status of children with myelomeningocele. fournal of Pediatric Psychology, 10(3), 325-336. https://doi.org/10.1093/jpepsy/10.3.325

Skreden, M., Skari, H., Malt, U. F., Pripp, A. H., Björk, M. D., Faugli, A., \& Emblem, R. (2012). Parenting stress and emotional wellbeing in mothers and fathers of preschool children. Scandinavian fournal of Public Health, 40(7), 596-604. https://doi.org/10.1177/1403494812460347

Tafarodi, R. W., \& Swann, W. B. (1995). Self-liking and self-competence as dimensions of global self-esteem: Initial validation of a measure. Journal of Personality Assessment, 65(2), 322-342. https://doi.org/10.1207/s15327752jpa6502_8

Teti, D. M., \& Gelfand, D. M. (1991). Behavioral competence among mothers of infants in the first year: The mediational role of maternal self-efficacy. Child Development, 62(5), 918-929. https://doi.org/10.2307/1131143

Tsermentseli, S., \& Kouklari, E. (2019). Impact of child factors on parenting stress of mothers of children with autism spectrum disorder and intellectual disability: A UK school-based study. Early Child Development and Care. Advance online publication. https://doi.org/10.1080/03004430.2019.1658090

Vance, A. J., \& Brandon, D. H. (2017). Delineating among parenting confidence, parenting self-efficacy, and competence. Advances in Nursing Science, 40(4), 18-37. https://doi.org/10.1097/ANS.0000000000000179

Vanderkerken, L., Heyvaert, M., Onghena, P., \& Maes, B. (2019). The relation between family quality of life and the family-centered approach in families with children with an intellectual disability. Fournal of Policy and Practice in Intellectual Disabilities, 16(4),

296-311. https://doi.org/10.1111/jppi.12317 
Walden, S., Pistrang, N., \& Joyce, T. (2000). Parents of adults with intellectual disabilities: Quality of life and experiences of caring. Journal of Applied Research in Intellectual Disabilities, 13(2), 62-76. https://doi.org/10.1046/j.1468-3148.2000.00002.x

Whipple, E. E., \& Webster-Stratton, C. (1991). The role of parental stress in physically abusive families. Child Abuse \& Neglect, 15(3), 279-291. https://doi.org/10.1016/0145-2134(91)90072-L

Wittkowski, A., Garrett, C., Calam, R., \& Weisberg, D. (2017). Self-report measures of parental self-efficacy: A systematic review of the current literature. Journal of Child and Family Studies, 26(1), 2960-2678. https://doi.org/10.1007/s10826-017-0830-5

World Health Organization. (2009). International statistical classification of diseases and related health problems (10th revision). Geneva, Switzerland: Author.

Zukosky, K. (2009). Self-efficacy: A concept analysis. Nursing Forum, 44(2), 93-102. https://doi.org/10.1111/j.1744-6198.2009.00132.x

\section{About the Authors}

Sanja Jandric works as a psychologist at the Unit for Child and Adolescent Psychiatry, Clinical Hospital Center in Osijek, Croatia. She is a $\mathrm{PhD}$ candidate at Biomedicine and Health Sciences program at Faculty of Medicine in Osijek with a thesis in child and adolescent psychiatry. She has previously work at a psychologist in two schools and Center for neglected and abused children. Apart from her masters in psychology, she has attained additional training in Neurofeedback/biofeedback and Tomatis. She is also a founder of an NGO An association for early intervention in Osjecko-Baranjska County, where she works with children with developmental disabilities, emotional and social problems.

Ana Kurtovic, $\mathrm{PhD}$ is an associate professor at the Department of Psychology at Faculty of Humanties and Social Sciences, University of J. J. Strossmayer in Osijek, Croatia, where she teaches courses in clinical psychology and developmental disabilities. She is the head of the Psychological Counseling Center for Students at the University of J. J. Strossmayer, where she works as a counselor. Apart from her masters and $\mathrm{PhD}$ education, she has training in Cognitive-behavioral therapy, Acceptance and commitment therapy, Compassion focused therapy, Shema therapy as well as Child assault prevention (CAP) and safeTALK-suicide alertness for everyone. 